\title{
Formability evaluation of carbon fiber NCF by a non-contact 3D strain measurement system and the effects of blank folder force on its formability
}

\author{
K. Tanaka ${ }^{1}$, R. Ushiyama ${ }^{1}$, T. Katayama ${ }^{1}$, S. Enoki ${ }^{2}$ \\ \& H. Sakamoto ${ }^{3}$ \\ ${ }^{1}$ Department of Biomedical Engineering, Doshisha University, Japan \\ ${ }^{2}$ Nara National College of Technology, Japan \\ ${ }^{3}$ Graduate School of Science and Technology, \\ Kumamoto University, Japan
}

\begin{abstract}
Non-Crimp Fabric (NCF) consists of unidirectional plies, which are kept together by stitching yarns arranged in a number of different orientations relative to the fabric production direction. Since NCF has no crimp, NCF can take full advantage of the continuous carbon fibers.

As NCF is deformed mainly due to shear deformation, it is difficult to form 3D shapes from it. Therefore, formability improvement of NCF by slitting a textile preform has been attempted; however, problems such as strength degradation at a notch and cost increase due to the increase of working process have occurred. So, it is necessary to improve formability of NCF without slitting. One of the methods of formability improvement is to use blank holder force. In previous studies, though the influence of blank holder force on formability of woven fabrics has been clarified, that on formability of NCF is uncertain.

In this study, the hemisphere geometry punch drape test was conducted to evaluate the influence of blank holder force on the formability of NCF. Meanwhile, deformation of NCF during the drape test was measured by a non-contact 3D strain measurement system.

Keywords: carbon fibers, non-crimp fabric (NCF), blank holder force, non-contact $3 D$ strain measurement system, drape test.
\end{abstract}




\section{Introduction}

To achieve the mass production of CFRP components, it is necessary to develop low-cost molding methods. For intermediate materials, Non-Crimp Fabric (NCF), which consists of unidirectional fiber plies that are kept together by stitching yarns arranged in a number of different orientations relative to the fabric production direction, has attracted much attention [1-3]. The use of NCF has simplified the laminating process compared to that of pre-impregnated unidirectional tapes (UD) by changing the arrangement and direction of the fiber tows, so the molding cost is expected to be reduced. This structure leads to an advantageous combination of high material properties, low cost processing, and excellent drape performance so it is also suitable for molding composite materials of complex shape [4]. Composite materials using NCF have begun to be used for the complex structural components of aircraft, automobiles, wind turbines and blades [5-7]. The textile preform like NCF is created by shaping and laminating, however, ease of following the shape of the mold is different, depending on the type of the substrate at the time of shaping the three-dimensional shape having a curved surface. Traditionally, as it was confirmed by molding actually whether the substrate was shapable to three-dimensional shape or not, it took a lot of effort, lacked accuracy and it was difficult to design the perform in mass production. Furthermore, large local deformations occur when the curved textile preform is shaped. These deformations affect the local orientations of fabrics, volume fraction of fibers and fiber thicknesses and become a factor in causing defects such as cracks and wrinkles and the degree of impregnation of resins. In addition, these affect the quality of appearance and mechanical property of the molded components. Therefore, it is required to evaluate the formability accurately whether it is possible to shape cleanly without local deformation of textile preform and wrinkles or not. Though NCF has been reported to be superior in formability to woven fabrics [8-11], there is no method or criteria for evaluating the formability, and the effect of stitch parameters, such as differences in stitch intensity and method on the formability of NCF has not yet been clarified.

As NCF is deformed mainly due to shear deformation, it is difficult to form 3D shapes [12]. Therefore, formability improvement of NCF by slitting a textile preform has been attempted; however, problems have occurred such as strength degradation at a notch and cost increase due to the increase of working process. It is therefore necessary to improve the formability of NCF without slitting. One method of formability improvement is to use a blank holder. In previous studies, though the influence of blank holder force on formability of woven fabrics has been clarified [13] that on formability of NCF is uncertain. In this study, a hemisphere geometry punch draping test was conducted to evaluate the influence of blank holder force on the formability of NCF. Meanwhile, deformation of $\mathrm{NCF}$ during the draping test was measured by a non-contact $3 \mathrm{D}$ strain measurement system. 


\section{Material and experimental procedure}

\subsection{Material}

Biaxial carbon fiber Non-Crimp Fabric (NCF), $0^{\circ} / 90^{\circ}$, was used. Table 1 shows the condition of the NCF. Polyester sewing thread is used for the stitching yarn. The stitching pattern of the NCF is tricot stitch (as shown in Fig. 1).

\subsection{Experimental}

Fig. 2 shows the schematic view of drape tests by hemisphere punch. The drape tests were conducted by a universal testing machine (Autograph AG-100kNX, Shimadzu Co. Ltd.) and measurement of shear angles of carbon fiber bundles was conducted by a non-contact 3D deformation measurement system (ARAMIS ${ }^{\circledR}$, GOM mbH). Diameters of the hemisphere punch shape are $100 \mathrm{~mm}$. The specimen size is $200 \mathrm{~mm} \times 200 \mathrm{~mm}$. A random pattern was applied to the specimen using air spray paint mixed with ethanol calcium carbonate in order to enable deformation analysis by a non-contact 3D deformation measurement system. Then, the specimen was placed on an acrylic palate of $300 \mathrm{~mm} \times 300 \mathrm{~mm}$ with a hole of $110 \mathrm{~mm}$ in diameter in the center, sandwiched by the blank holder, and set on the stage. There are three conditions of the blank holder. First, the acrylic plate of $300 \mathrm{~mm} \times 300 \mathrm{~mm}$ with a hole of $110 \mathrm{~mm}$ in diameter in the center was used to apply a load that was uniformly distributed over the entire specimen (test A). Second, the blank holder B shown in Fig. 3 was used (test B). It is considered that the shear deformability of the specimen can be improved by doing the following: the tensile load is applied outward of the specimen which is held only in $\pm 45^{\circ}$ directions at the edge and opened in $0^{\circ} / 90^{\circ}$ directions (as shown in Fig. 4). Third, the blank holder was not used and nothing was put on the specimens (test C). Fourth, applying outward of the specimen which is held only in $0^{\circ} / 90^{\circ}$ directions at the edge and opened in $\pm 45^{\circ}$ directions by using the blank holder B (test D). Fig. 5 shows the condition of examination. Subsequently, the hemisphere punch was set on the test machine and the drape tests were conducted by pushing the specimens with the displacement rate of $10 \mathrm{~mm} / \mathrm{min}$. During the tests, the state of deformation was measured by non-contact 3D deformation measurement system (ARAMIS ${ }^{\circledR}, \mathrm{GOM} \mathrm{mbH}$ ). We compare the results of tests $\mathrm{A}, \mathrm{B}, \mathrm{C}$ and $\mathrm{D}$ in order to clarify the effect of blank holder.

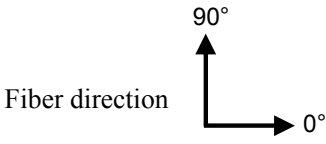

Figure 1: NCF with tricot stitching.

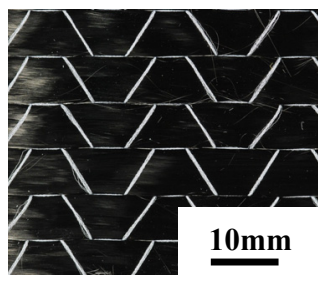

(a) Surface

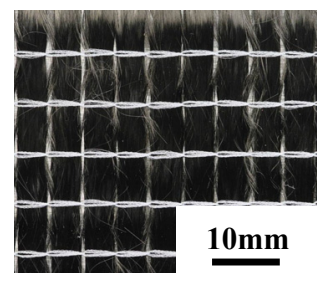

(b) Back side 
Table 1: $0^{\circ} / 90^{\circ}$ Specimens condition.

\begin{tabular}{cccc}
\hline Specimens & $\begin{array}{c}\text { Stitch } \\
\text { type }\end{array}$ & $\begin{array}{c}\text { Thickness } \\
{[\mathrm{mm}]}\end{array}$ & $\begin{array}{c}\text { Area } \\
\text { density } \\
{\left[\mathrm{g} / \mathrm{m}^{2}\right]}\end{array}$ \\
\hline \multirow{2}{*}{ NCF } & Tricot & 0.40 & 300 \\
\hline
\end{tabular}

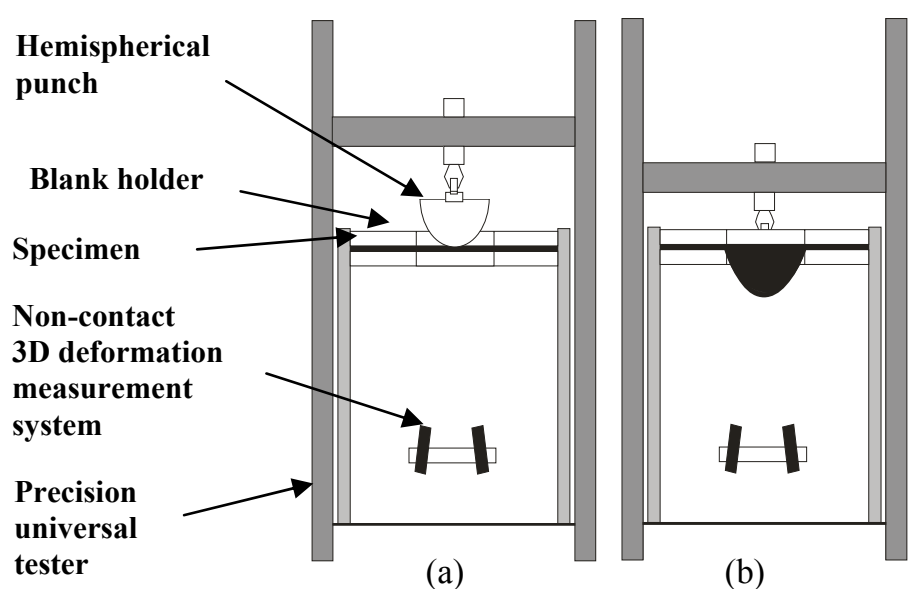

Figure 2: Schematic drawing of draping test: (a) before test; (b) after test.

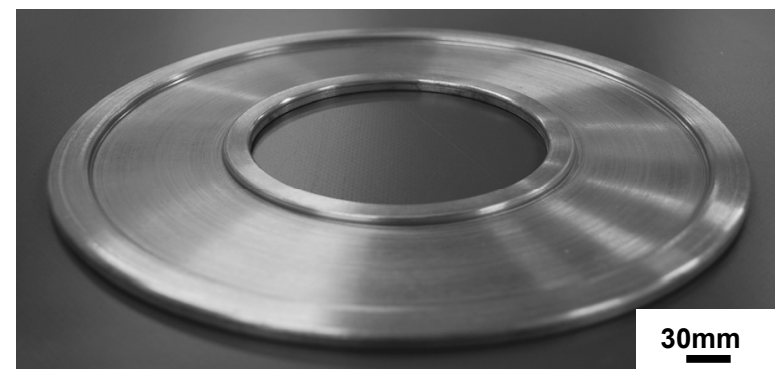

Figure 3: Blank holder B. 


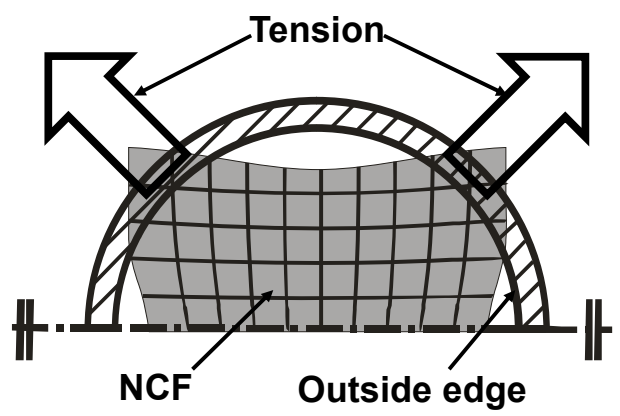

Figure 4: Schematic of blank holder B function.

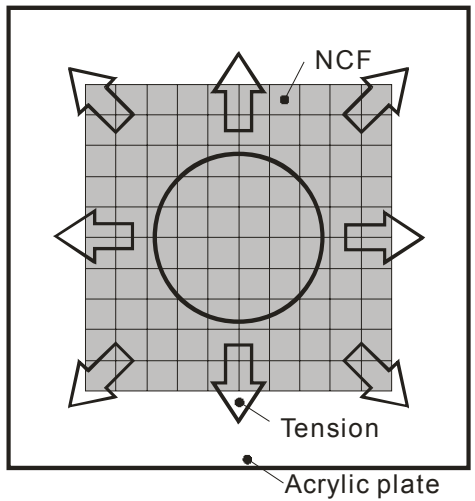

(a)

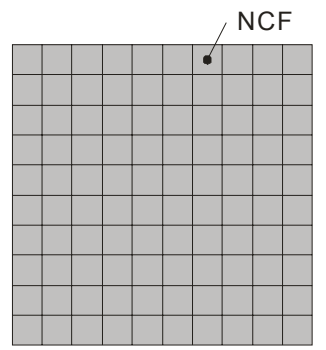

(c)

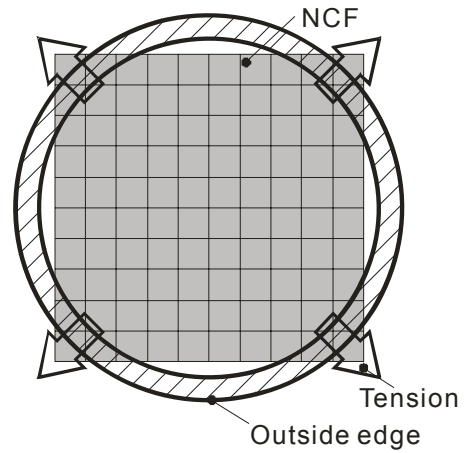

(b)

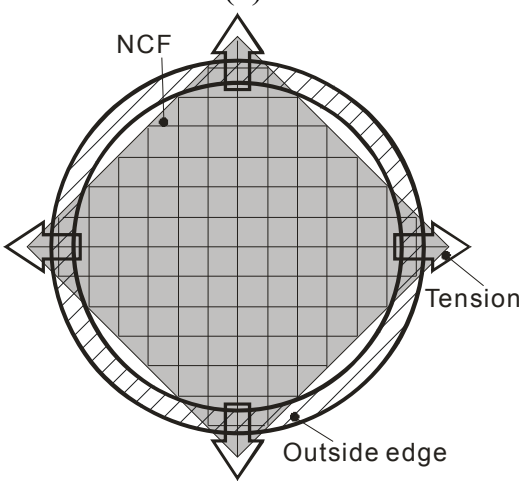

(d)

Figure 5: Condition of examination. (a) Test A; (b) Test B; (c) Test C; (d) Test D. 
A non-contact 3D deformation measurement system uses a principle of digital image correlation and is a measuring device which can evaluate from the viewpoint of quantitative and qualitative non-uniform deformation of the measured object. In this study, we created an area called "facets" in the specimen (as shown in Fig. 6) and measured deformation of facets. Shear angle $\theta_{\text {ARAMIS }}$ is calculated from equation (1). Here, $\alpha$ is the angle [deg] between two directional fibers after deformation (as shown in Fig. 6).

$$
\theta_{\text {ARAMIS }}=90^{\circ}-\alpha
$$

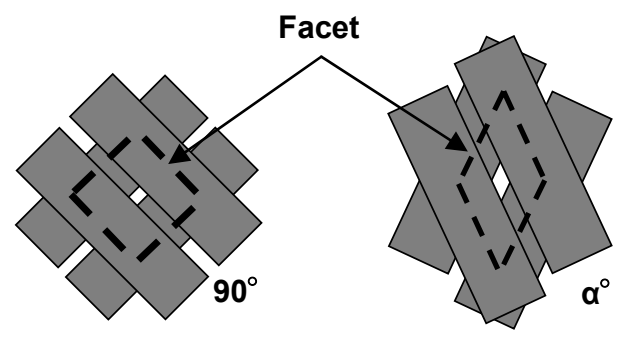

Figure 6: Schematic drawing of facet deformation.

\section{Results and discussion}

\subsection{The hemispherical draping test}

Fig. 7 shows an example for the distribution of shear deformation of NCF in the punch displacement for $20 \mathrm{~mm}$ obtained by a hemispherical drape test. Fig. 8 shows NCF after deformation in this test. Shear deformation occurred in $\pm 45^{\circ}$ directions to the fiber direction. Therefore, to evaluate the formability of NCF, shear deformations in $\pm 45^{\circ}$ directions was used in this study. Fig. 9 shows each measuring point for the shear deformations in $\pm 45^{\circ}$ direction. Fig. 10 shows the

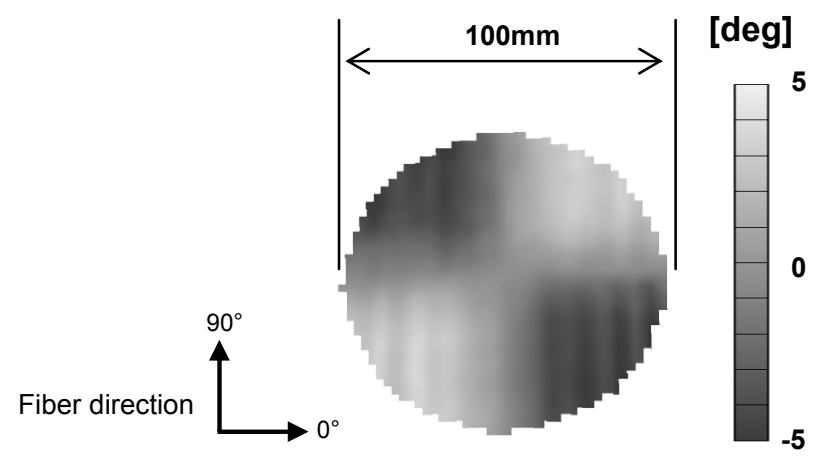

Figure 7: Contour of shear angle. 


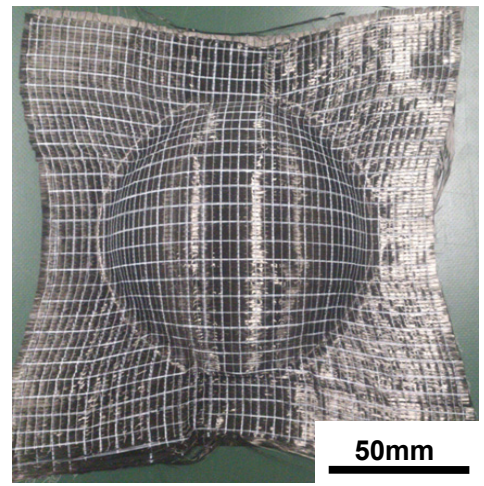

Figure 8: NCF formed by hemispherical head punch.

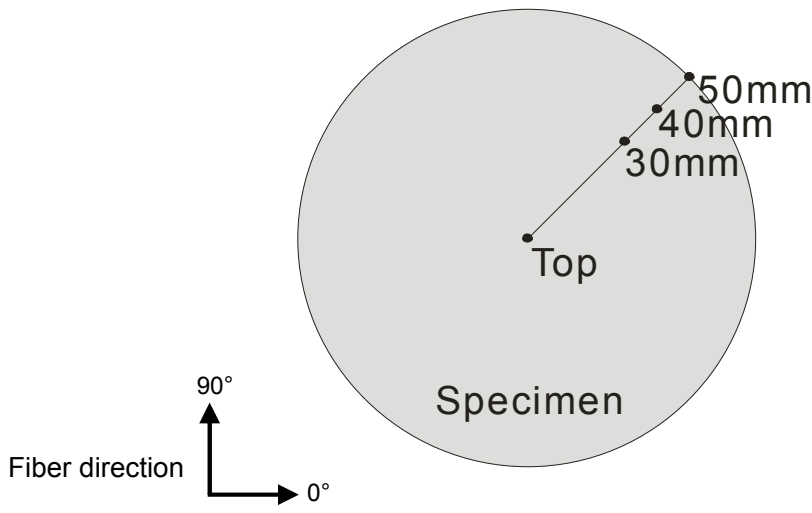

Figure 9: Measuring point for the shear deformation in $\pm 45^{\circ}$ direction.

relationship between the punch displacement and the shear angles at the point of $40 \mathrm{~mm}$ from the top of the hemisphere. There is a point where the slope of the line changed during the test. It is considered that this is because the fiber bundles came into contact with each other due to the shear deformation which was prevented.

It was defined in this study that the shear angle at the point where the slope of the line changed was the angle of shear deformable limit and the indicator of the formability. In this study, we call this point, intersection of two approximate lines, "Locking Angle". 


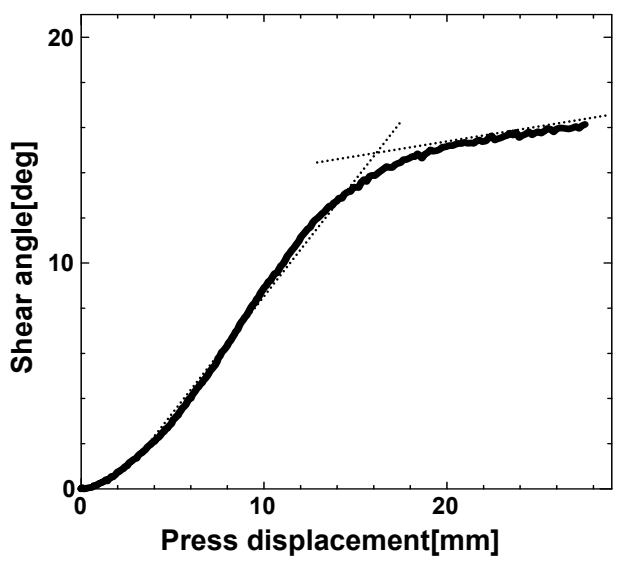

Figure 10: Relationship between shear angle and punch displacement.

\subsection{Formability improvement of NCF by blank holder force}

Fig. 11 shows Locking Angles at the point of $30 \mathrm{~mm}, 40 \mathrm{~mm}$ and $50 \mathrm{~mm}$ from the top of the hemisphere in $\pm 45^{\circ}$ directions to the fiber direction. Locking Angles were indicated to be larger in test B, followed by test A and test C. Fig. 12 shows Locking Angles at the point of $30 \mathrm{~mm}, 40 \mathrm{~mm}$ and $50 \mathrm{~mm}$ from the top of the hemisphere for test B and test D. A Locking Angle for test B, in which $\pm 45^{\circ}$ directions to the fiber direction was held by blank holder and the edges in $0^{\circ} / 90^{\circ}$

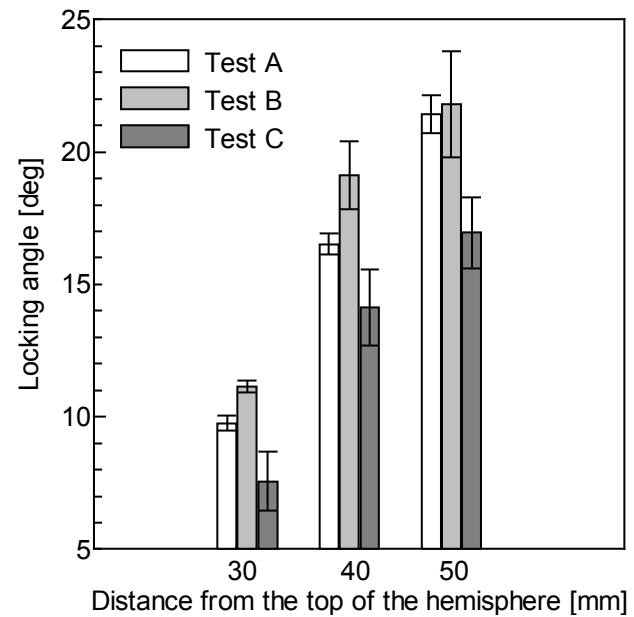

Figure 11: Relationship between the locking angle distances from the top of the hemisphere. 


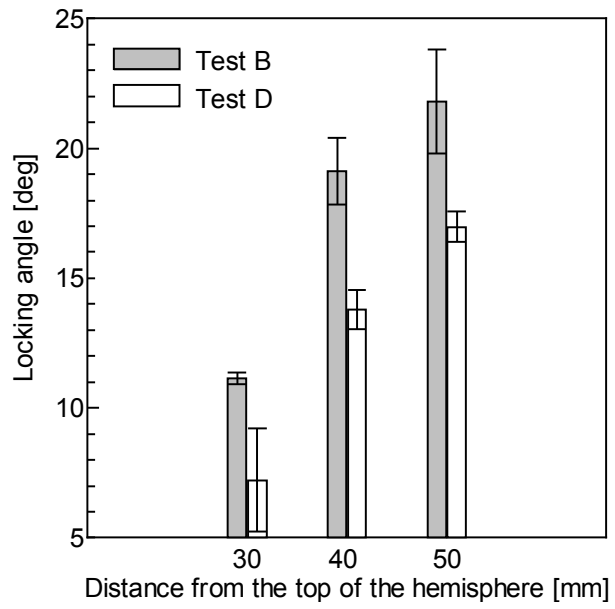

Figure 12: Relationship between the locking angle distances from the top of the hemisphere.

directions are opened, was larger than that for test $\mathrm{D}$, in which $0^{\circ} / 90^{\circ}$ directions to the fiber direction was held by blank holder and the shear deformability of Locking Angles in $\pm 45^{\circ}$ directions were improved by applying a tensile load in $\pm 45^{\circ}$ directions and removing it in $0^{\circ} / 90^{\circ}$ directions for the orientation of the fiber bundles.

\section{Conclusions}

A hemisphere geometry punch drape test was conducted to evaluate the influence of blank holder force on formability of NCF. Meanwhile, deformation of NCF during the drape test was measured by a non-contact 3D strain measurement system. The effect of blank holder force on formability of $\mathrm{NCF}$ was evaluated and the method to improve formability was proposed. The investigation yielded the following conclusions:

1. The blank holder force improved formability of Non-Crimp Fabric (NCF).

2. Shear deformability of locking angles in $\pm 45^{\circ}$ directions were improved by applying the tensile load in $\pm 45^{\circ}$ directions and removing it in $0^{\circ} / 90^{\circ}$ directions for the orientation of the fiber bundles.

\section{Acknowledgement}

This study was partially supported by the high technological research project at "Research and Development Center for Advanced Composite Materials" of Doshisha University and Ministry of Education, Culture, Sports, Science and Technology, Japan. 


\section{References}

[1] U. Beier, F. Fischer, J.K.W. Sandler, V. Altstadt, Christian Weimer, Wolfgang Buchs, Mechanical performance of carbon fibre-reinforced composites based on stitched preforms, Composites: Part A, Vol. 38, pp. 1655-1663 (2007).

[2] Jun-Liang Zhao, Tao $\mathrm{Fu}$, Yong Han, Ke-Wei Xu, Reinforcing hydroxyapatite/thermosetting epoxy composite with 3-D carbon fiber fabric through RTM processing, Materials Letters, Vol. 58, pp. 163-168 (2003).

[3] K. Tanaka, T. Katayama, N. Kohashi, Y. Kinoshita, K. Uno, Compression Molding of Carbon Fiber Reinforced Thermoplastics Using Non-Woven Stitched Multi-Axial Cloth by Means of Induction Heating System, Journal of the Society of Materials Science, Japan, Vol. 58, No. 7, pp. 642-648 (2009).

[4] T.C. Truong, M. Vettori, S. Lomov, I. Verpoest, Carbon composites based on multi-axial multi-ply stitched performs. Part 4: Mechanical properties of composites and damage observation, Composites: Part A, Vol. 36, pp. 1207-1221 (2005).

[5] Ch.V. Katsiropoulos, Sp. G. Pantelakis, B.C. Meyer, Mechanical behavior of non-crimp fabric PEEK/C thermoplastic composites, Theoretical and Applied Fracture Mechanics, Vol. 52, pp. 122-129 (2009).

[6] M. Ozawa, H. Satake, Development of CFRP Body for LFA, Jidoushagijyutu, Vol. 64, No. 7, pp. 52-57 (2010).

[7] K. Shindo, N. Kawasetsu, K. Takita, E. Kato, VaRTM Manufacturing Process of Large Size FRP by Vacuum Assisted Resin Transfer Molding, Technical Report of Mitsubishi Heavy Industry, Vol. 43, No. 1, pp. 11-12 (2006).

[8] W.R. Yu, P. Harrison, A. Long, Finite element forming simulation for non-crimp fabrics using a non-orthogonal constitutive equation, Composites: Part A, Vol. 36, pp. 1079-1093 (2005).

[9] S.V. Lomov, I. Verpoest, Carbon composites based on multiaxial multiply stitched preforms. Part 2. KES-F characterization of the deformability of the preforms at low loads, Composites: Part A, Vol. 34, pp. 359-370 (2003).

[10] S.V. Lomov, I. Verpoest, R. Loendersloot, Carbone composites based on multiaxial multiply stitched preforms. Part 5: geometry of sheared biaxial fabrics, Composites: Part A, Vol. 37, pp. 103-113 (2006).

[11] J. Hu, Y. Jiang, Modeling formability of multiaxial warp knitted fabrics on a hemisphere, Composites: Part A, Vol. 33, pp. 725-734. (2002).

[12] Ph. Boisse, E. Deluycker, K. Vanclooster, F. Morestin, S.V. Lomov, I. Verpoest, D. Vandepitte, Full-field strain measurements in textile deformability studies, Composites: Part A, Vol. 39, pp. 1232-1244 (2008).

[13] Y. Nakamura, T. Tomiso, Press Forming of Glass-Cloth Reinforced Thermo-Plastic Sheet, Journal of the Society of Materials Science, Japan, Vol. 43, No. 487, pp. 395-401 (1994). 